\title{
Race, Cultural Capital, and Schooling: An Analysis of Trends in the United States
}

\author{
Matthijs Kalmijn \\ Utrecht University \\ Gerbert Kraaykamp \\ Nymegen University
}

\begin{abstract}
Using survey data on Blacks and Non-Hispanic Whites in 1982 and 1985, the authors examine the link between racial inequality in schooling and differences in cultural capital-the degree to which parents socialize their children into high-status culture. The findings indicate a significant increase in parental cultural capital across birth cohorts (from 1900 to 1960). That this increase has been faster among Blacks than among Whites and persists after Black-White differences are taken into account suggests a degree of racial integration in the cultural domain. The results also show that exposure to high-status culture is associated with higher levels of schooling and that the integration of Blacks into high-status culture has contributed to the Black-White convergence in schooling. The latter finding illustrates that cultural capital may serve as a route to upward mobility for less privileged minority groups.
\end{abstract}

$\mathrm{D}$ ifferences in schooling are a key factor in the debate on racial inequality in American society. As is well known, the Black-White gap in schooling has narrowed over the course of this century, but even in recent cohorts, Blacks remain at a disadvantage. Although American research has examined several causes underlying this trend (Farley and Allen 1989), the European tradition of research on cultural capital may provide another answer. Using individual survey data on cultural socialization, we examine the link between racial inequality in schooling, on the one hand, and exclusion in the cultural domain, on the other hand. More specifically, we assess whether racespecific trends in educational attainment in the 20th century are related to changes in exposure to Euro-American high-status culture in Black and White families.

\section{CULTURAL CAPITAL AND RACIAL INEQUALITY}

\section{Racial Differences in Schooling}

The American history of racial inequality in schooling can be roughly divided into three periods (Smith 1984). Shortly after Emancipation in 1863, there were signs that schooling was expanding more rapidly among Blacks than among Whites. During Reconstruction, the difference in average years of schooling completed by Black and White men declined from 4.39 for men born before 1865 , to 3.18 for men born in the 1880 s. This period of convergence was followed by a 20 -year period of divergence. After 1896, educational opportunities for Blacks were blocked by the so-called separate-but-equal doctrine. As a consequence of this doctrine, all public schools became segregated by race, and Black schools received considerably less governmental support than did white schools. The salaries of teachers in White schools, for example, were about 
twice as high as those of teachers in Black schools, and pupil-to-pupil ratios in Black schools were 1.7 times as high as in White schools (Card and Krueger 1992). The gap in years of schooling for Black men in the second period increased from 3.02 for men born in the $1880 \mathrm{~s}$ to 3.46 for men born at the beginning of the 20th century. In the third and longest period, Black-White differences in schooling declined again, even though school segregation persisted until 1954, when it was finally declared unconstitutional in Brown $v$. Board of Education. The schooling gap in the third period decreased from 3.46 for men born at the beginning of this century to .83 for men born in the 1950s. Similar patterns are observed for women (Smith 1984).

Despite the long-term decline of educational inequality in the third period, a racial gap in educational attainment remains. In 1988, the gap between Blacks and Whites aged 25-34 in years of completed schooling was still .66 years (Farley and Allen 1989). This difference seems modest, but a small difference in average years of schooling is caused by large underlying differences in high school and college completion. For example, in 1988, 83 percent of Black men aged 25-34 were high school graduates, compared to $91 \%$ of White men. For college graduates, the proportions were 15 percent for Blacks and 28 percent for Whites.

Several factors help explain why a gap in schooling exists. First, the quality and financial support of precollege education in predominantly Black schools has generally been lower than that of predominantly White schools (Card and Krueger 1992). As a result Black students are often not as well prepared to enter and complete college as are White students. A second explanation focuses on racial differences in family background. On average, Black parents have lower levels of schooling and lower family incomes than do White parents. Blacks are also more likely than are Whites to grow up in broken homes and to have more siblings on average. Since all these factors affect children's schooling, part of the gap in schooling can be explained by the less favorable family resources of Black students (Duncan 1968; Grusky and DiPrete 1990; Haveman and Wolfe 1994). Third, with regard to the more recent turnaround in racial inequality, racial differences in schooling can be linked to problems of the inner-city population. The most prominent hypothesis in this respect was suggested by Wilson (1987), who argued that the exodus of Black middle-class families from the inner city has left lower-class blacks with few role models of achievement. In this line of reasoning, the prevalence of unemployment, lowquality jobs, and illegal sources of income in the inner city has lowered the motivation of Black youths to invest in schooling.

\section{Cultural Capital and Educational Inequality}

A second and different line of research on educational inequality has focused on the effects of cultural capital on educational attainment. Cultural capital usually refers to socialization into highbrow cultural activities, and this concept includes a variety of tastes and behaviors, such as interest in art and classical music, attendance at theaters and museums, and reading literature. The leading proponent of this tradition is the French sociologist Bourdieu. One of Bourdieu's (1973) contributions to stratification research was the development of a new answer to the old question of how socioeconomic advantages are transmitted across generations. In general, Bourdieu argued that in a time of the rapid expansion of higher education, cultural capital arose as a new ascriptive force in the status-attainment process. More specifically, he contended that children from high socioeconomic backgrounds are more often exposed to highbrow cultural activities at home and that those who acquire cultural capital at home are more likely to do well in school and subsequently to have better chances of achieving high levels of schooling than others. Together, these arguments imply that differences in cultural capital explain part of the asso- 
ciation between the socioeconomic positions of parents and their children.

Cultural capital is believed to be an asset in the schooling process for several reasons: Children who are exposed to cultural capital may be better prepared to master academic material, may develop a greater taste for learning abstract and intellectual concepts, and may be favored directly by teachers over children who have less cultural capital. A lack of cultural capital may discourage students to stay in school (self-selection) may hamper their accomplishments while in school (indirect exclusion), or may lead to a lack of recognition from teachers (teacher selection). Although there is a debate about which of these mechanisms is most likely to operate, empirical studies have generally underscored the role of cultural capital in the schooling process.

In one of the first systematic American empirical studies on cultural capital, DiMaggio (1982) showed that a student's involvement in art, music, and literature is positively correlated with his or her grades in high school, even after the influence of prior ability and father's education is taken into account. In a later study, DiMaggio and Mohr (1985) also found significant effects of the respondents' cultural capital on years of schooling completed (after controlling for father's education and occupational prestige) and noted that differences in cultural capital explained about 14 percent of the effect of father's education on a respondent's schooling. A drawback of these two studies is that they focused entirely on the cultural interests and activities of students. Thus, it remains somewhat uncertain whether the measures of cultural capital are causally prior to outcomes in schooling. Another way to measure cultural capital is to use indicators of parents' cultural participation (Teachman 1987). This is a somewhat stronger measure because parents' cultural activities are unlikely to be affected by their children's schooling. Using a large longitudinal data set on high school seniors, Teachman found positive effects of parental cultural resources on children's educational attainment.
In European countries, researchers generally have found similar results. For the Netherlands, De Graaf (1986) showed that parental cultural capital has significant effects on educational attainment, after controlling for father's and mother's schooling and father's occupational prestige; cultural capital explained 9 percent (oldest cohort) to 14 percent (youngest cohort) of the effect of parental socioeconomic status (SES) on educational attainment. De Graaf (1988) found positive results for West Germany as well, although the effect of cultural capital was limited to success at the highest level of secondary schooling (the gymnasium). In a comparative study, Mateju (1990) stated that cultural capital explained part of the effect of parental SES on schooling in Czechoslovakia (13 percent), Hungary (20 percent), and the Netherlands (21 percent). Similar results for Hungary were found by Ganzeboom, De Graaf, and Robert (1990).

In sum, both American and European studies have underscored the role of cultural capital in the schooling process. Socialization into high-status culture appears to have a strong effect on educational attainment. At the same time, however, the degree to which cultural capital explains the association between socioeconomic origins and destinations is relatively modest: in the range of 15 percent.

\section{Synthesis and Research Questions}

So far, few studies have applied notions of cultural capital to ethnic or racial differences in schooling. Most studies have focused either on European countries, where ethnic minorities are small, or on the United States, but have limited the analyses to Whites. An exception is Farkas, Grobe, Sheehan, and Shuan (1990), who examined the interaction between teachers and students of different ethnic groups from a cultural capital perspective. A more relevant exception for our aims is DiMaggio and Ostrower's (1990) comparison of Black-White differences in cultural participation. Although that study did not address inequality in socioeconomic outcomes per se, it presented several find- 
ings that served as a starting point for our analysis. Using the 1982 Survey of Public Participation in the Arts, DiMaggio and Ostrower showed that there are important racial differences in arts consumption. On the one hand, Whites are more likely to attend classical music, opera, and ballet performances and to visit art museums and historical monuments. On the other hand, Blacks are more likely to engage in traditional African American art forms, such as listening to jazz and blues, attending jazz and blues concerts, and watching these art forms on television. Although a large part of these differences can be attributed to Black-White differences in schooling, the effects of race remain significant after the influence of father's and mother's educational attainment is taken into account.

A more important finding, at least from our perspective, is that similar differences exist when one focuses on childhood experiences: Socialization into highbrow cultural activities is more common in White families than in Black families, even after differences in parental education are taken into account. DiMaggio and Ostrower (1990) further claimed that over time, there has been no convergence between Blacks and Whites with respect to participation in highbrow cultural activities. They interpreted this finding as being an indication of "cultural resistance." That is, in the face of increased socioeconomic opportunities, Blacks have remained attached to traditional Black art forms to maintain their cultural identity. Hence, despite the long-term convergence of Blacks and Whites in several other respects, such as income, education, and intermarriage, DiMaggio and Ostrower argued that Blacks have maintained their distance from traditional White culture. This model of resistance is in contrast to the cultural behavior of Whites. DiMaggio and Ostrower pointed out that over time, Whites have become integrated into traditional Black culture, such as jazz, blues, and soul music.

In this article we answer the following three questions:
1. How have cultural resources changed across birth cohorts of Blacks and Whites?

2. To what extent can these changes be explained by changes in family background?

3. Have changes in family background and cultural resources contributed to the Black-White convergence in schooling?

If cultural capital is relevant for the influence of class background on educational attainment, as previous work has shown, it should be relevant for other ascriptive factors, such as race, as well. Following DiMaggio and Ostrower (1990), we argue that cultural capital (as measured in studies of educational attainment) is part of the Euro-American cultural tradition and that selection or self-selection on the basis of cultural capital in the schooling career can be understood as a mechanism through which racial inequality in American society is strengthened. In contrast to DiMaggio and Ostrower's hypothesis of cultural resistance, however, we expected that as intergroup contact has increased and overt racial discrimination has decreased, racial segmentation with respect to tastes and lifestyles has also declined. If such a convergence in cultural resources has occurred, we expected it to have contributed to the convergence in schooling. In a more general sense, we tried to examine whether segmentation with respect to cultural tastes and lifestyles in American society has implications for trends in racial inequality. Hence, our analysis focuses not so much on why Whites have an advantage over Blacks in schooling, but more on the question of why Blacks have been catching up over time.

\section{THE DATA}

The data we analyzed came from the 1982 and 1985 waves of the Survey of Public Participation in the Arts (SPPA) that contains a set of questions on arts consumption, parental background, and cultural socialization. The survey was done in conjunction with the National Crime Survey and was a random probability sample of the American population. The 1982 and 1985 questions we used were formulated in an identical 
fashion, and questions on parents' participation in the arts were directed to a subset of the sample. We limited our comparisons to Black and non-Hispanic White men and women aged 25 and over, since some younger persons would still be enrolled in school. The total number of respondents was $6,248,5,660$ of whom were non-Hispanic White and 588 were Black.

The SPPA is unique in providing data on cultural socialization, but it also has limitations. As is the case in most surveys containing questions on family background, no retrospective information is available on parental income. Although parental income has important effects on educational attainment, studies in the Netherlands (Ganzeboom 1982) have shown that income has little effect on the consumption of high-status culture once the influence of education has been taken into account. ${ }^{1}$ As a result, our model is incomplete, but our estimates of the effect of cultural socialization on schooling are hardly biased. Similar arguments can be made about other determinants of schooling, such as the number of siblings and family structure. The only concern that remains is the omission of father's occupation, which has a small effect on both cultural socialization and children's schooling (Ganzeboom 1982).

\section{DESCRIPTIVE ANALYSES}

We start out by describing how cultural socialization and schooling have changed across birth cohorts and how these trends differ for Blacks and Whites. The top panel of Figure 1 presents mean levels of schooling by race and birth cohort. Our cohorts ranged from persons born in 1900 to persons born in 1960 . Respondent's schooling was measured in single years of completed schooling, ranging from 0 for no schooling to 20 years for Ph.D.s $(M=12.2 ; S D=3.2)$. Our results are generally consistent with findings from other studies: a rapid increase in educational attainment and a steady narrowing of the racial gap since the beginning of this century. It should be kept in mind that selective mortality from older cohorts may have led to a modest understatement of the true trend.

The middle panel of Figure 1 depicts trends in parental education. Father's and mother's schooling were measured in six categories. We recoded categories to the weighted midpoints in years of schooling (using data on the respondent's education broken down by sex). In 14 percent of the cases, educational data on both parents were missing. Missing values were imputed, using data on years of schooling by race, birth cohort, and sex as published in Smith (1984). From Figure 1, it is clear that the average level of parental education has increased during the 20th century for both Whites and Blacks. Hence, family resources have become more favorable for both races, though there appears to have been little convergence.

Our results are consistent with what several other researchers have found on the basis of larger data sets (Farley and Allen 1989; Smith 1984). What makes the SPPA survey unique is that it allowed us to examine trends in parental cultural capital. Following Lamont and Lareau (1988:156), cultural capital can be defined as "institutionalized, i.e., widely shared high status cultural signals (attitudes, preferences, formal knowledge, behaviors, goods, and credentials) used for social and cultural exclusion." Although limited in scope, our data contain several key indicators of highstatus cultural behavior. More specifically, we considered four parental activities: whether parents attended performances of classical music, plays, and art museums and encouraged the respondent to read books (not for school). All items are respondents' reports of what parents did when the respondents were aged 15. Possible answers were "never," “occasionally," and "often." For the lack of other information, we assumed equal distances between categories. ${ }^{2}$ Subsequently, we used the unweighted average of scores on the four variables as an index of parental cultural capital. The index ranges from 0 (for no exposure at all) to 2 (for "often" on all four items) and has a reliability of $\alpha=$ .73 , which is reasonable for a scale of four items. For purposes of presentation, 

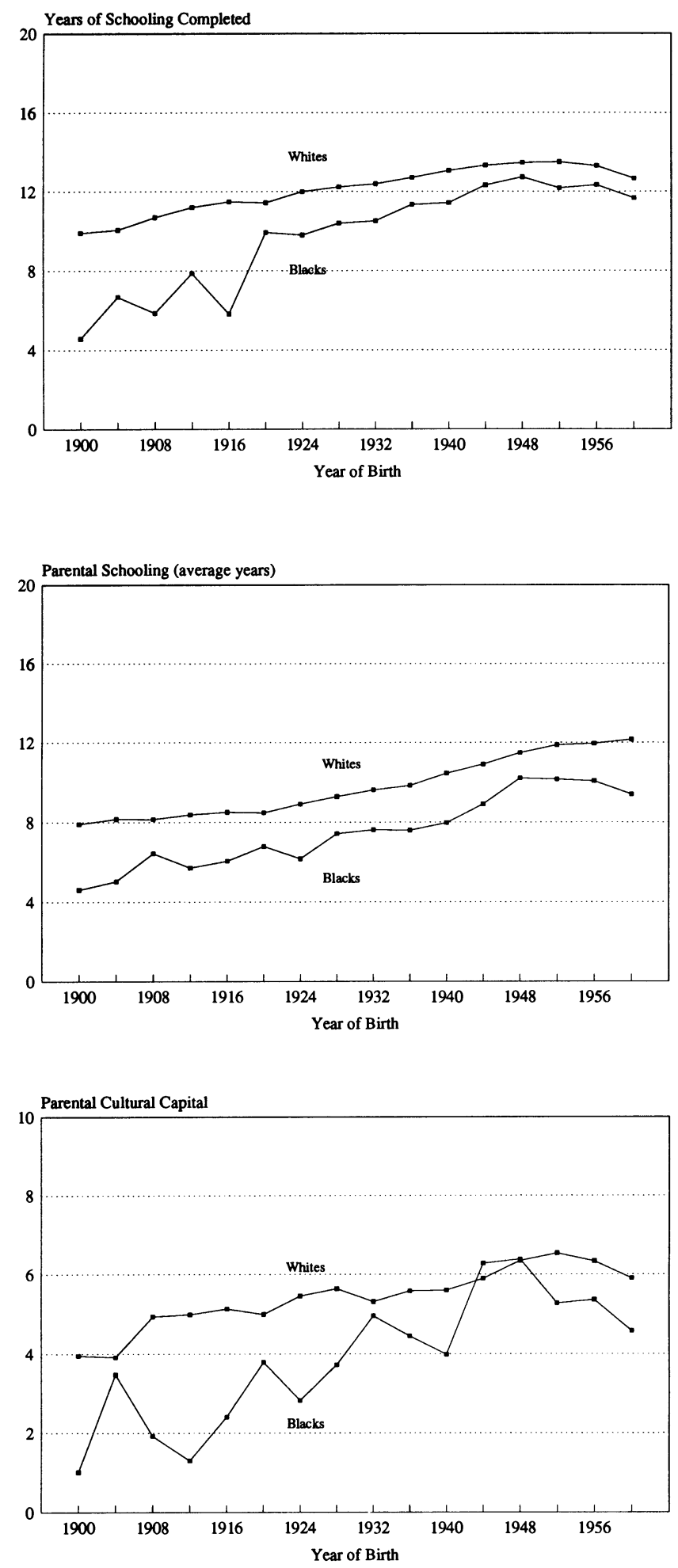

Figure 1. Years of Schooling Completed, Parental Schooling, and Parental Cultural Capital, by Race and Year of Birth: Survey of Public Participation in the Arts, 1982-85 
we multiplied the index by $10(M=5.5$; $S D=5.0$ ).

The bottom panel of Figure 1 presents mean levels of cultural capital broken down by birth cohort and race. Since our scale pertains to the same age (age 15) for all respondents, differences among birth cohorts provide a view of trends that is not confounded by age effects. In this respect, our analyses improve on DiMaggio and Ostrower's (1990) comparison of respondent's current cultural participation across birth cohorts. Figure 1 shows that across cohorts, there has been a clear increase in parental cultural capital. In most cohorts, however, the mean for Blacks is well below the mean for Whites, indicating that Blacks are disadvantaged with respect to cultural capital. The cohort averages fluctuate because of the relatively small number of Blacks in most cohorts, but at first glance, the racial gap in acquired cultural capital appears to have narrowed.

In sum, there has been an increase in schooling and family resources for both Blacks and Whites. For Blacks, however, the increase in schooling and parental cultural capital has occurred at a faster rate, leading to a convergence in both domains. The question thus arises: Have changes in racial inequality in the cultural domain contributed to changes in the inequality of schooling?

\section{MULTIVARIATE ANALYSES}

\section{Methodological Approach}

To explain race-specific trends in cultural capital and schooling, we estimated and compared two regression models for each outcome (cultural capital and schooling). Though the actual models for cultural capital and schooling differ, the specification of trends is identical, and we therefore limit our methodological discussion to the more general case. Our first model, Model A, includes cohort, race, and interactions of cohort by race. The interactions allow trends in cultural capital or schooling to be different for Blacks and Whites and are specified as follows for this model:

$$
\begin{aligned}
Y_{i}= & \beta_{\text {constant }}+\beta_{\text {black }_{\text {BLACK }}} \text { BLK }_{i} \\
& +\beta_{\text {black trend }} \text { BLACK }_{i} \\
& \times \text { COHORT }_{i} \\
& +\beta_{\text {white trend }} \text { WHITE }_{i} \\
& \times \text { COHORT }_{i}+\epsilon_{i}
\end{aligned}
$$

where $Y_{i}$ is the dependent variable for the ith individual (cultural capital or schooling), BLACK $_{i}$ is 1 for Blacks (0 otherwise), $\mathrm{WHITE}_{i}$ is 1 for whites (0 otherwise), and $\mathrm{COHORT}_{i}$ is the year of birth. The cohort variable is rescaled by subtracting 1,900 and dividing by 10 . Because of the way interaction effects were specified in Model A, all coefficients have a meaningful interpretation:

- $\beta$ constant is the average $Y_{i}$ of Whites born in 1900 .

- $\beta_{\text {black }}$ is the disadvantage of Blacks compared to Whites in 1900.

- $\beta_{\text {black trend }}$ is the increase in $Y_{i}$ for Blacks per decade.

- $\beta_{\text {white trend }}$ is the increase in $Y_{i}$ for Whites per decade.

- $\beta_{\text {black trend }}-\beta_{\text {white trend is the Black- }}$ White convergence in $Y_{i}$ per decade.

In the second model (Model B), we added a set of $j$ background characteristics (father's education, mother's education, rural residence, and sex in the model of cultural capital; father's education, mother's education, rural residence, sex, and parental cultural capital in the model of schooling):

$$
\begin{aligned}
Y_{i}= & {[\text { Model A] }} \\
& +\Sigma_{i j} \beta_{j} \text { BACKGROUND }_{i j}+\epsilon_{i}
\end{aligned}
$$

The difference between Model A and Model $\mathrm{B}$ lies in the interpretation of the trend effects. In Model B, the trends can be seen as "net trends," that is, trends after the influence of changes in background characteristics has been taken into account. The trends in Model A, in contrast, can be considered "total trends." The difference between a "net" and a "total" trend tells which part of a trend can be explained by changes in background characteristics. Because interactions of cohort and race are included, the models are able to address three separate questions: (1) the extent to which changes in Whites' background characteristics explain the White trend, (2) the extent to which changes in Blacks' background 
characteristics explain the Black trend, and (3) the extent to which changes in Black-White differences in background characteristics explain the Black-White convergence.

\section{Trends in Cultural Capital}

Our first research question was, How have cultural resources changed across birth cohorts for Blacks and Whites? To answer this question, we present estimates of our two regression models in Table 1. The coefficients we report are unstandardized, except for the effects of parental education. ${ }^{3}$ Model A shows that in 1900, Blacks had 2.67 points less cultural capital than did Whites. Since the mean of the scale is 5.5 , this finding indicates that Blacks were at a notable disadvantage at the beginning of the 20th century. When considering trends, we observed that among Whites, there has been a significant increase in cultural capital of .40 points per decade; over the entire period (until the 1960 cohort), this finding implies an increase of 2.37 points. Among Blacks, the in-

Table 1. Regression of Parental Cultural Capital on Selected Characteristics: Survey of Public Participation in the Arts, $1982-85(N=6,248)^{\mathrm{a}}$

\begin{tabular}{|c|c|c|}
\hline \multirow[b]{2}{*}{ Variables } & \multicolumn{2}{|c|}{$\begin{array}{c}\text { Trends in Parental } \\
\text { Cultural Capital }\end{array}$} \\
\hline & Model A & Model B \\
\hline Black (0/1) & $\begin{array}{l}-2.674^{\star \star} \\
(-5.20)\end{array}$ & $\begin{array}{l}-1.133^{\star} \\
(-2.28)\end{array}$ \\
\hline Black trend $(1900=0)$ & $\begin{array}{l}.770^{* *} \\
(6.28)\end{array}$ & $\begin{array}{l}-.041 \\
(-.36)\end{array}$ \\
\hline White trend $(1900=0)$ & $\begin{array}{l}.396^{\star *} \\
(9.79)\end{array}$ & $\begin{array}{l}-.326^{* *} \\
(-8.14)\end{array}$ \\
\hline Father's education ${ }^{\mathrm{b}}$ & & $\begin{array}{l}.264^{\star *} \\
(16.42)\end{array}$ \\
\hline Mother's education ${ }^{\mathrm{b}}$ & & $\begin{array}{l}.240^{* *} \\
(14.51)\end{array}$ \\
\hline Rural residence $(0 / 1)$ & & $\begin{array}{l}-.711^{* *} \\
(-6.11)\end{array}$ \\
\hline Woman $(0 / 1)$ & & $\begin{array}{l}1.117^{* *} \\
(10.19)\end{array}$ \\
\hline Constant & $\begin{array}{l}-1.258 \\
(-8.13)\end{array}$ & $\begin{array}{c}1.092 \\
(6.35)\end{array}$ \\
\hline Adjusted $R^{2}$ (percentage) & 2.6 & 25.5 \\
\hline
\end{tabular}

crease is greater (.77). Hence, cultural resources have increased at a faster rate for Black children than for White children. More specifically, the racial difference in cultural capital has declined by $.77-.40=.37$ per decade. This convergence is statistically significant ( $t$-value is 2.9). This finding implies that for cohorts born in 1960, almost no difference between Blacks and Whites remains $(2.674-6 \times .37=.42)$. This result is consistent with the convergence observed in the bottom panel of Figure 1.

That there has been a convergence contradicts DiMaggio and Ostrower's (1990) hypothesis of cultural resistance. After comparing respondents' cultural capital by age and race, DiMaggio and Ostrower concluded that there has been no racial integration in the cultural domain. Since their analysis was based on respondents' cultural capital at one point in time (1982), their comparison confounded age and cohort (or period) effects. Because our analysis was based on respondents' cultural socialization at a specific stage in their life cycle (age 15), our cohort comparisons are not affected by age effects and hence are more plausible.

To what extent can these trends be attributed to the rise in parental education across cohorts? To answer this question, we included father's and mother's education in Model B. We also took into account several other characteristics: rural residence, woman, year of survey, and two indicators for missing values on parental schooling variables. Rural residence was coded 1 for people living in rural areas and 0 otherwise. ${ }^{4}$ The variable woman was coded 1 for women and 0 for men. Year of survey was included to control for possible differences in cultural capital between the 1982 and 1985 samples. We also included a dummy variable indicating whether educational data were missing for both parents (for Blacks and Whites separately); this variable adjusts for possible selectivity bias owing to respondents who did not report parental data.

Model B in Table 1 shows that the net trend for Whites is negative and statistically significant $(-.33)$, indicating that net of family background, there has been 
a decline in the amount of cultural capital that White parents provide their children. In other words, once we took into account that parental education has risen over time, no increase in cultural capital remained. That the effect is negative, rather than 0 , indicates that White parents with a given amount of education currently provide their children with less cultural capital than parents with the same amount of education did some decades ago. Apparently, interest in high culture has not kept up with the rapid expansion of higher education. ${ }^{5}$ This finding corresponds to the pessimistic beliefs of popular critics like Postman (1985) and Hirsch (1988) regarding the level of cultural literacy in American society. The results for Blacks are different; no statistically significant trend-negative or positive-was left after we controlled for changes in background characteristics. Apparently, Black parents with a given amount of education currently provide their children with the same amount of cultural capital as they did before. Blacks have more cultural capital now because there are more highly educated Black parents.

When focusing on how Black-White differences change across cohorts, we observed that net of changing background characteristics, the convergence is $-.04-[-.33]=.29$ per decade $(t$ value is 2.5 , which is statistically significant). When we compared this finding to the convergence in Model A $.77-.40=$ .37), we saw that 22 percent of the racial convergence in cultural capital can be explained by race-specific changes in background. In other words, changes in family background are important, but even after we took family influences into account, Blacks are still catching up to Whites with respect to cultural capital.

The other effects of Model B in Table 1 are generally consistent with what we expected. Both father's and mother's education have positive effects on cultural socialization; the (standardized) effects are .26 and .24, respectively, indicating that the influence of parents' education is reasonably strong. The relationship between education and cultural capital in the parental generation is consistent with research on arts consump- tion that has found that of all the factors affecting participation in the arts, education is the most relevant (Ganzeboom 1982). We also found that rural residents have less cultural capital than do urban residents, probably because there are fewer, if any, theaters and museums in rural areas.

The table further indicates that women have more cultural capital than do men. At first, this finding may seem odd, since in a random sample, the parents of women must have exactly the same characteristics as the parents of men. A possible interpretation is that parents encourage their daughters more often than their sons to read. Another interpretation is that daughters more frequently report on their mothers, whereas sons more frequently report on their fathers. If mothers are more encouraging with regard to participation in high culture, daughters would report higher levels of cultural capital than would sons. ${ }^{6}$

\section{Trends in Educational Attainment}

Although the net gain in cultural capital among Blacks may be important in its own right, its relevance ultimately depends on how it has affected racial inequality in other domains of the stratification system. Therefore, we examined what part of the educational difference between Blacks and Whites can be explained by differences in cultural capital. Regression models for individual differences in educational attainment are reported in Table 2; the coefficients are unstandardized, except for the effects of parental education and cultural capital. Model A shows that in the 1900 cohort, Blacks had 4.3 fewer years of schooling than did Whites. Among Blacks, there has been a strong increase in schooling of 1.27 years per decade. Among Whites, there has been an increase as well, but not as strong $(.63$ years per decade). When comparing these two trends, we observed that the convergence in schooling is $1.27-.63=$ .65 per decade. This convergence is statistically significant ( $t$-value is 8.5). That Blacks have made gains in schooling relative to Whites is consistent with 
Table 2. Regression of Years of Schooling Completed on Selected Characteristics: Survey of Public Participation in the Arts, $1982-85(N=6,248)^{\mathrm{a}}$

\begin{tabular}{|c|c|c|c|}
\hline \multirow[b]{2}{*}{ Variables } & \multicolumn{3}{|c|}{ Trends in Years of Schooling Completed } \\
\hline & Model A & Model B1 & Model B2 \\
\hline Black (0/1) & $\begin{array}{l}-4.309^{* *} \\
(-14.11)\end{array}$ & $\begin{array}{l}-3.522^{\star *} \\
(-11.67)\end{array}$ & $\begin{array}{l}-3.334^{* *} \\
(-11.48)\end{array}$ \\
\hline Black trend $(1900=0)$ & $\begin{array}{l}1.274^{* *} \\
(17.51)\end{array}$ & $\begin{array}{l}.828^{* *} \\
(12.20)\end{array}$ & $\begin{array}{l}.834^{* *} \\
(12.78)\end{array}$ \\
\hline White trend $(1900=0)$ & ${ }^{.626^{* *}}$ & $\begin{array}{l}.195^{* *} \\
(7.99)\end{array}$ & $\begin{array}{l}.249^{* *} \\
(10.56)\end{array}$ \\
\hline Father's education $^{\mathrm{b}}$ & & $\begin{array}{l}.203^{* *} \\
(13.29)\end{array}$ & $\begin{array}{l}.135^{* *} \\
(8.96)\end{array}$ \\
\hline Mother's education ${ }^{b}$ & & $(15.02)$ & $\begin{array}{l}.174^{* *} \\
(11.30)\end{array}$ \\
\hline Rural residence $(0 / 1)$ & & $\begin{array}{l}-.292^{\star *} \\
(-4.13)\end{array}$ & $\begin{array}{l}-.174^{* *} \\
(-2.55)\end{array}$ \\
\hline Woman $(0 / 1)$ & & $\begin{array}{l}-.344^{* *} \\
(-5.17)\end{array}$ & $\begin{array}{l}-.530^{* *} \\
(-8.20)\end{array}$ \\
\hline Parental cultural capital ${ }^{\mathrm{b}}$ & & & $\begin{array}{l}.259^{* *} \\
(22.42)\end{array}$ \\
\hline Constant & $\begin{array}{r}10.245 \\
(111.43)\end{array}$ & $\begin{array}{r}12.167 \\
(116.53)\end{array}$ & $\begin{array}{c}11.986 \\
(118.94)\end{array}$ \\
\hline Adjusted $R^{2}$ (percentage) & 16.0 & 32.9 & 37.9 \\
\hline
\end{tabular}

cohort comparisons using larger data sets (Smith 1984).

To examine the underlying causes of these trends, we estimated two additional models. The first model (B1) added parental education (and other background characteristics) and therefore allowed us to take into account that parental education has changed across cohorts. The second model (B2) added parental cultural capital and permitted us to take into account that there has been a convergence in cultural capital as well. Hence, in this context we had to compare the total trend with two net trends.

Model B1 in Table 2 shows that the net trend for Whites is positive and statistically significant (.20), indicating that an increase in schooling remains, even after changes in parental education have been taken into account. The net trend for Whites is 31 percent of the total trend, indicating that 69 percent of the trend can be explained. The results are similar for Blacks; the trend declined by 35 percent, from 1.27 to .83 . Hence, changes in family background can explain part of the increase in schooling within racial groups.
In Model B2, we added the effect of cultural capital. For Blacks, the net trend in schooling is about the same as in Model B1, showing that changes in cultural capital have not contributed to the increase in schooling. For Whites, we observed a different pattern: The trend coefficient increased once the influence of cultural capital was taken into account. The trends were .195 per decade, in Model B1 and .249 per decade in Model B2. The interpretation of this increase lies in the way in which cultural capital has changed across cohorts. As Table 1 shows, levels of parental education have risen. Given this improvement, however, there has been a relative decline in parental cultural capital for Whites. In other words, the increase in parental cultural resources had not kept up with the increase in parental education. This relative loss in the quantity of cultural capital has had a downward pressure on the trend in schooling among Whites. When we controlled for this downward pressure in Model B2, we found that levels of schooling increased faster. Substantively, this finding means that the level of schooling of Whites would have 
increased faster had there not been a relative decline in cultural capital.

Are race-specific changes in family background and cultural capital also responsible for changes in differences in schooling between Blacks and Whites? To answer this question, we subtracted the trend coefficient for Whites from the trend coefficient for Blacks. Table 2 shows that the Black-White convergence in schooling decreases from .65 in Model A, to .63 in Model B1, and to .59 in Model B2. In other words, changes in parental education explain 2 percent of the convergence. Given parental education, changes in cultural capital explain another 8 percent of the convergence. Hence, declining racial differences in culture, as we measured them, have a positive but modest impact on how racial inequality in schooling has changed. This effect arises more from a relative decline in the cultural resources of Whites than from an improvement in the cultural resources of Blacks.

To what extent does cultural capital explain the influence of parental education on schooling, another ascriptive variable in the stratification process? Table 2 shows that the (standardized) effect of parental cultural capital on schooling is positive and moderately strong $(\beta=.26)$. In addition, we found that both father's and mother's education positively affected a respondent's education. To assess the extent to which cultural capital explains class differences, we compared the standardized effects of parental education in Model B2 and B1 and observed that the effect of father's education declined by 33 percent (from .20 to .14), while that of mother's education declined by 26 percent (from .24 to .17). Thus, about a third of the influence of parental education is indirect, via the influence of cultural capital. Although parental education is not the same as class background, this finding indicates that cultural capital plays an important role in the transmission of socioeconomic advantages across generations. $^{7}$

\section{DISCUSSION}

When using parental characteristics to examine trends in cultural capital, we found a significant increase in participation in traditionally Euro-American culture. That this increase has been faster among Blacks than among Whites and persists after Black-White differences in parental education are taken into account shows that there has been a certain degree of racial integration in the cultural domain. This finding is consistent with changes in other dimensions of racial integration, such as intermarriage (Kalmijn 1993); occupational segmentation; and, to some extent, income differences (Farley and Allen 1989). In addition, we found that in all cohorts and for both races, more exposure to cultural capital is associated with higher levels of schooling after other background characteristics are taken into account. This finding confirms Bourdieu's (1973) thesis of cultural reproduction and extends it to an important ethnic minority in American society. Furthermore, we observed that the integration of Blacks in traditionally Euro-American culture has made a positive though modest contribution to the Black-White convergence in schooling.

Our findings give rise to two more general conclusions. With respect to growing racial equality in American society, we conclude that the integration of Blacks in Euro-American high culture has made a positive contribution to the relative gains of Blacks in the educational system. However, we also believe that the role of cultural capital is modest in comparison to the well-known influence of legal and institutional changes in American society, such as school desegregation, busing, scholarships for Blacks, and affirmative action. How the effect of cultural integration on schooling compares to the role of the improved economic position of Blacks is difficult to assess at this point. To answer this question, we would need specific information on both the cultural and financial resources in the parental home.

With respect to Bourdieu's thesis, we believe that our findings point to another way in which cultural capital may operate. Previous studies showed that cultural socialization generally explains a significant part of the influence of class background on socioeconomic achieve- 
ment. This finding has generally been interpreted in terms of reproduction or the persistence of inequality. According to this reasoning, ascriptive variables like father's occupation and education maintain their force in modern societies through the process of cultural socialization. In this article, we focused on a different and more persistent ascriptive force in modern society-race-and reached a somewhat different conclusion. By showing that cultural capital explains part of the Black-White convergence in schooling, we illustrated that cultural capital may also serve as a route to upward mobility for less privileged groups in society.

\section{NOTES}

1. As far as we know, comparable analyses for the United States are unavailable. Using the 1982 wave of the SPPA, we estimated a regression model of respondent's participation in high-status culture using household income, occupational prestige, and education as independent variables. (We controlled for sex, race, and rural residence.) Our analyses indicated that there is virtually no effect of income $(\beta=.036$, standardized, $p=.048)$. The effect of education is much larger $(\beta=.370)$, while the effect of occupational prestige is modest but not trivial $(\beta=$ .093).

2. With the available data, there are two other ways to approach this issue. One is to use eight dummy variables $-4 \times(3-1)=$ 8 -but doing so would be unwieldy, particularly when cultural capital is the dependent variable. Other scaling methods for nominal variables, such as HOMALS, use information on the dependent variable to develop scale values (see Vrooman and Dronkers 1986). Since such procedures maximize the correlation between the scale and other variables in the model, they make coefficients more difficult to interpret.

3. We do no report standardized effects for cohort, race, and the interaction of cohort and race because such effects have no meaningful interpretation.

4. We would have preferred residence while growing up, but this information was not available in the SPPA. Because many urban residents have grown up in rural areas, this variable underestimates the actual ruralurban difference in schooling.
5. Although this result seems to suggest that high culture is not as exclusive as it used to be, we found little evidence for such a trend. We estimated a model of cultural capital that includes interactions of cohort and parental education and found no statistically significant decrease across cohorts in the effect of parental education on cultural socialization. Thus, the audience for high culture is as exclusive now as it was some decades ago, at least with respect to education.

6. The dummy variables for missing values on parental education have significant negative effects on parental cultural capital (not reported). Since we used race-, sex- and cohort-specific means to impute missing values on parental education, this finding means that respondents who did not report their parents' education have less cultural capital than did the average educated person in their particular cohort and race-sex group. We also examined models without missing data but found that the effects of other variables were virtually identical. Year of survey (not reported) has no significant effect, indicating that the background characteristics of the respondents in the two surveys were comparable.

7. Consistent with previous research, we found that rural residents have lower levels of educational attainment than do urban residents and that women have lower levels than do men.

\section{REFERENCES}

Bourdieu, Pierre. 1973. "Cultural Reproduction and Social Reproduction." Pp. 71-112 in Knowledge, Education, and Cultural Change, edited by R. Brown. London: Tavistock.

Card, David and Alan W. Krueger. 1992. "School Quality and Black-White Relative Earnings: A Direct Assessment." Quarterly Journal of Economics 107:151-200.

De Graaf, Paul M. 1986. "The Impact of Financial and Cultural Resources on Educational Attainment in the Netherlands." Sociology of Education 59:237-46.

. 1988. "Parents' Financial and Cultural Resources and Transition to Secondary School in the Federal Republic of Germany." European Sociological Review 4:209-21.

DiMaggio, Paul. 1982. "Cultural Capital and School Success: The Impact of Status Culture Participation on the Grades of U.S. High School Students." American Sociological Review 47:189-201.

DiMaggio, Paul and John Mohr. 1985. "Cul- 
tural Capital, Educational Attainment, and Marital Selection." American Journal of Sociology 90:1231-61.

DiMaggio, Paul and Francie Ostrower. 1990. "Participation in the Arts by Black and White Americans." Social Forces 68:75378.

Duncan, Otis Dudley. 1968. "Inheritance of Poverty or Inheritance of Race?" Pp. 85110 in Perspectives on Poverty: On Understanding Poverty, edited by Daniel P. Moynihan. New York, Basic Books.

Farkas, George, Robert P. Grobe, Daniel Sheehan, and Yuan Shuan. 1990. "Cultural Resources and School Success: Gender, Ethnicity, and Poverty Groups within an Urban School District." American Sociological Review 55:127-42.

Farley, Reynolds and Walter R. Allen. 1989. The Color Line and the Quality of Life in America. New York: Oxford University Press.

Ganzeboom, Harry B. G. 1982. "Explaining Differential Participation in High-Cultural Activities: A Confrontation of InformationProcessing and Status-Seeking Theories." Pp. 186-205 in Theoretical Models and Empirical Analyses, edited by Werner Raub. Utrecht: E.S.-Publications.

Ganzeboom, Harry B. G., Paul M. De Graaf, and Peter Robert. 1990. "Cultural Reproduction Theory on Socialist Ground." Research in Social Stratification and Mobility 9:79-104.

Grusky, David B. and Thomas A. DiPrete. 1990. "Recent Trends in the Process of Stratification." Demography 27:617-37.
Haveman, Robert and Barbara Wolfe. 1994. Succeeding Generations: On the Effects of Investments in Children. New York: Russell Sage Foundation.

Hirsch, E. D. 1988. Cultural Literacy. New York: Vintage Books.

Kalmijn, Matthijs. 1993. "Trends in Black/ White Intermarriage.” Social Forces 72:11946.

Lamont, Michèle and Annette Lareau. 1988. "Cultural Capital: Allusions, Gaps and Glissandos in Recent Theoretical Developments." Sociological Theory 6:153-68.

Mateju, Peter. 1990. "Family Effect on Educational Attainment in Czechoslovakia, the Netherlands and Hungary." Pp. 187-210 in Social Reproduction in Eastern and Western Europe, edited by J. L. Peschar. Groningen, the Netherlands: Oomo.

Postman, Neil. 1985. Amusing Ourselves to Death. New York: Viking Press.

Smith, James P. 1984. "Race and Human Capital." American Economic Review 74: 685-98.

Teachman, Jay D. 1987. "Family Background, Educational Resources, and Educational Attainment." American Sociological Review 52:548-57.

Vrooman, C. J. and J. Dronkeers. 1986. "Changing Educational Attainment Processes: Some Evidence from the Netherlands." Sociology of Education 59:69-78.

Wilson, William Julius. 1987. The Truly Disadvantaged: The Inner City, the Underclass, and Public Policy. Chicago: University of Chicago Press.

Matthijs Kalmijn, Ph.D., is Associate Professor, Department of Sociology, Utrecht University, the Netherlands. His main fields of interest and current work are in the areas of social stratification, demography, and race-ethnicity.

Gerbert Kraaykamp, Ph.D., is Assistant Professor, Department of Sociology, Nymegen University, the Netherlands. His main fields of interest and current work are in the areas of social stratification, lifestyles, and media consumption.

An earlier version of this article was presented at the biannual meeting of the Research Committee on Social Stratification (RC28) of the International Sociological Association, Zurich, 1995. Address all correspondence to Matthijs Kalmijn, Department of Sociology, Utrecht University, P.O. Box 80140, 3508 TC, Utrecht, the Netherlands, or by e-mail at socw42@pswx1.fsw.ruu.nl. 